\title{
Parental Discipline and Externalizing Behavior Problems in Early Childhood: The Roles of Moral Regulation and Child Gender
}

\author{
David C. R. Kerr, ${ }^{1}$ Nestor L. Lopez, ${ }^{1}$ Sheryl L. Olson, ${ }^{1,2,3}$ and Arnold J. Sameroff ${ }^{1,2}$
}

Received February 13, 2003; revision received January 30, 2004; accepted February 4, 2004

\begin{abstract}
We tested whether individual differences in a component of early conscience mediated relations between parental discipline and externalizing behavior problems in 238 3.5-year-olds. Parents contributed assessments of discipline practices and child moral regulation. Observations of children's behavioral restraint supplemented parental reports. Parents and teachers reported on child externalizing symptoms. Parental induction, warm responsiveness, and less frequent use of physical punishment generally were associated with higher levels of moral regulation and fewer externalizing problems. Moreover, moral regulation partially mediated relationships between discipline and externalizing symptoms, with the clearest case of mediation involving induction. However, relationships were found for boys only. Results support a mediation model wherein inductive and physical discipline may influence the expression of boys' externalizing behavior through effects on conscience. Finally, results suggest that different developmental processes may be associated with early externalizing problems in boys and girls, and confirm that fathers' reports contribute to our understanding of the origins of child externalizing problems.
\end{abstract}

KEY WORDS: externalizing behavior problems; early childhood; parental discipline; conscience; gender differences.

\section{INTRODUCTION}

A growing body of research highlights the importance of examining the development of externalizing behavior problems across early childhood. Once established, externalizing behavior problems show moderate stability through early childhood (Achenbach, Edelbrock, \& Howell, 1987; Keenan, Shaw, Delliquadri, Giovannelli, \& Walsh, 1998), and preschool externalizing behaviors, in turn, predict continued problems into the elementary school years (Campbell, Shaw, \& Gilliom, 2000). However, even clinically significant manifestations of externalizing problems may reflect normal struggles with

\footnotetext{
${ }^{1}$ Department of Psychology, University of Michigan, Ann Arbor, Michigan.

${ }^{2}$ Center for Human Growth and Development, University of Michigan, Ann Arbor, Michigan.

${ }^{3}$ Address all correspondence to Sheryl L. Olson, Department of Psychology, University of Michigan, 525 East University, Ann Arbor, Michigan 48109-1109; e-mail: slolson@umich.edu.
}

developmental changes (Campbell, 1995). For example, approximately half of preschool children with significant externalizing symptoms no longer manifest these behaviors after their transition to school (Campbell et al., 2000; Keenan \& Wakschlag, 2000). Because some children's externalizing symptoms are stable across multiple developmental periods, it is important to identify developmental risk factors that differentiate children with chronic behavior problems from children whose problems remit.

Two salient risk factors linked to childhood externalizing behaviors are considered here: individual differences in children's ability to regulate moral conduct and variations in parental discipline practices. The purpose of this study was to evaluate a conceptual model that integrates previous findings on relationships among parental discipline, child moral regulation, and child externalizing behavior problems. These relationships were examined in a sample of special significance, young children at risk for persistent conduct problems. 


\section{Moral Regulation: A Developmental Risk Factor for Childhood Conduct Problems}

The ability to regulate moral conduct has important conceptual connections to behavior problems. Diagnoses associated with externalizing symptoms, such as oppositional defiant disorder, are characterized by active defiance of rules and requests, relational difficulties stemming from ignoring others' needs (American Psychiatric Association [APA], 2000), and other indications of inadequate moral internalization. Additionally, criteria for a diagnosis of conduct disorder, which is often preceded by early externalizing problems (Loeber, Lahey, \& Thomas, 1991), include violations of serious societal rules (APA, 2000). Yet, internalization and the development of rule-governed behavior reflect normal self-regulatory processes that can be considered conceptually distinct from externalizing behavior problems. Kochanska, DeVet, Goldman, Murray, and Putnam (1994) conceptualized "Active Moral Regulation/Vigilance" as a dimension of early conscience that includes a child's sensitivity to wrongdoing and appropriate conduct, ability to restrain herself from misbehavior, and tendency to correct damages through confession and reparation. Measures of this construct capture developmental skills necessary for everyday prosocial responses to challenging situations, but do not sample prototypic externalizing behaviors such as overt aggression, destructiveness, and overactivity (Achenbach, 1992; Kochanska et al., 1994). Also, measures of moral regulation correlate only moderately with externalizing symptoms (Olson, Kerr, Sameroff, \& Lopez, 2004), suggesting that, while some overlap may exist, moral regulation is not a "proxy" for early conduct problems.

Moral regulation can be reliably assessed in children as young as 2 years of age, providing a basis for studying how early conscience development may affect trajectories of problem behaviors (Kochanska et al., 1994). Indeed, this dimension of conscience has been found to relate directly to the severity of externalizing problems among 3.5year-olds (Olson, Kerr, et al., 2004). In contrast, individual differences in empathy and guilt, two other posited components of early conscience, have not been found to relate consistently to early externalizing behaviors. For example, although Hastings, Zahn-Waxler, Robinson, Usher, and Bridges (2000) found that less emotional concern for others predicts externalizing problems across the transition from early to middle childhood, they and others (e.g., MacQuiddy, Maise, \& Hamilton, 1987; Zahn-Waxler, Cole, Welsh, \& Fox, 1995) have not found this capacity to relate to preschoolers' externalizing problems. Similarly, Olson, Kerr, et al. (2004) recently found that reports of preschoolers' guilt were not associated with externalizing behaviors after accounting for moral regulation.

The temperament construct of effortful/inhibitory control has been theorized to underlie early disruptive behavior problems (Eisenberg, Cumberland, et al., 2001), and this may explain why moral regulation has more consistent linkages with externalizing symptoms than do other dimensions of conscience. Indeed, among preschoolers, lower levels of effortful/inhibitory control have been found to be associated both with higher behavior problem scores and with difficulty in regulating moral behavior (Kochanksa et al., 1994; Kochanska, Murray, Jacques, Koenig, \& Vandegeest, 1996; Olson, Sameroff, Kerr, Lopez, \& Wellman, 2004), but not with guilt. Thus, although theory suggests that lower levels of guilt and empathy should be implicated in disruptive behavior disorders, previous work in early childhood has found moral regulation to be more consistently related to externalizing behavior and its temperamental antecedents. Therefore, the present study will focus on moral regulation in relation to externalizing behavior problems.

\section{Effects of Parental Discipline on Moral Regulation}

It is not surprising that researchers have looked to specific parenting and discipline behaviors to explain individual differences in moral regulation, given the strong influence of parenting practices on the development of other processes related to self-regulation and social competence (e.g., Eisenberg, Losoya, \& Fabes, 2001; Grusec $\&$ Goodnow, 1994). Most researchers have concluded that whereas power-assertive methods may be related to immediate obedience, inductive discipline (i.e., reasoning, reminding children of rules, and explaining the impact of children's behavior on others) is more effective at promoting children's internalization, as evident in moral behavior that occurs without parental supervision (e.g., Grusec \& Kuczynski, 1980; Hoffman \& Saltzstein, 1967; Maccoby \& Martin, 1983). According to Hoffman (1983, 1994), effective discipline encounters must generate an optimal level of arousal in children. That is, sufficient arousal may help children attend to parents' inductive messages, whereas under- or overarousal may prevent children's appropriate processing.

Physical punishment is a form of power assertion that has been identified as an ineffective strategy for facilitating moral internalization, although it is commonly used by parents of young children (Hoffman, 1983; Straus \& Stewart, 1999). Unlike inductive techniques, physical punishment contains no message about alternative, appropriate behavior, focuses children's attention away from the 
consequences of their behavior for others, and may teach children to avoid getting caught rather than to curtail unacceptable behavior (reviewed in Gershoff, 2002). Physical discipline may even undermine internalization, because it encourages children to view their appropriate behavior as externally imposed rather than motivated by internal factors (Dix \& Grusec, 1983; Grusec \& Goodnow, 1994). Indeed, the negative association between children's experience of corporal punishment and their moral internalization received robust support in a recent meta-analysis by Gershoff (2002).

Research by Kochanska and colleagues supports the view that parents promote young children's internalization of norms through induction and a de-emphasis on power assertion. For example, Kochanska and Aksan (1995) reported that mothers of toddlers who showed committed compliance (a measure of internalization defined by enthusiastic adherence to a parental agenda without need for intervention) in a cleanup paradigm were more likely to use gentle guidance (e.g., reasoning, suggestions, polite requests) and less likely to utilize threats, physical punishment, and commands. These authors also found that maternal use of these latter forceful, negative control strategies was negatively related to child internalization, as reflected by the child's inability to resist playing with a prohibited toy when alone.

Dimensions of parental warmth and responsiveness also appear to be important influences on the development of child moral regulation (e.g., Gardner \& Ward, 2000). For example, Kochanska and Aksan (1995) demonstrated positive associations between maternal gentle discipline style (characterized as nurturant, responsive, and consistent) and indices of toddlers' internalized conduct. Furthermore, Kochanska and Murray (2000) successfully predicted child conscience at early school age from mother-child warmth and cooperation at toddlerhood and preschool age, even after controlling for the stability of early conscience.

\section{Discipline, Moral Regulation, and Externalizing Behavior Problems: An Integrative Model}

Parental disciplinary behaviors have been found to relate to externalizing behavior problems from toddlerhood through adolescence. For example, Gershoff (2002) recently documented clear associations between corporal punishment and child aggression in all 27 of the studies included in her meta-analysis. In contrast, "proactive parenting" (e.g., clear instruction, support, and limit setting) of preschoolers has been found to predict lower levels of externalizing symptoms over time (Denham et al., 2000).
Although direct and indirect links between parental discipline and child behavior problems have been reported, the processes by which discipline practices may influence the occurrence and developmental trajectory of externalizing behavior problems are not clearly understood. Some have explained this link by referring to self-regulatory competencies such as the internalization of norms, empathy, guilt, and altruism, all of which have been conceptualized as components of early conscience (e.g., Hoffman, 1983, 2000; Hoffman \& Saltzstein, 1967; Kochanska, 1993; Krevans \& Gibbs, 1996). Gardner and Ward (2000) summarized research suggesting that parenting behaviors are linked to the development of self-regulation according to internalized standards of conduct, which in turn are thought to underlie children's capacity to refrain from antisocial behavior in the absence of adult supervision. However, there have been no empirical studies integrating the interrelations among parental discipline, child conscience, and externalizing problems in one coherent model. We propose a theoretical model in which discipline practices influence the occurrence of externalizing problems by affecting the moral regulation component of early conscience proposed by Kochanska (1993).

\section{Child Gender Differences}

There are a number of reasons why relationships among parental discipline, child moral regulation, and externalizing symptoms may differ depending on child gender. First, girls and boys may differ on overall levels of moral internalization. For example, in early childhood, girls show higher levels of guilt, empathy, and social cognitive maturity, all of which have conceptual connections to moral development (Kochanska et al., 1994; Kochanska, Gross, Lin, \& Nichols, 2002; Zahn-Waxler et al., 1995). Second, parents may use different types and/or levels of discipline with boys and girls, which, in turn, may affect children's internalization of parental messages and expression of problem behavior. For example, mothers of 2-year-olds more often respond to girls' than boys' moral transgressions by explaining the consequences of offenses to the rights and needs of others (Smetana, 1989). Third, the relationships between some types of parental discipline and child outcomes may be moderated by child gender. For example, according to meta-analyses, correlations between parenting behaviors and child externalizing are stronger for boys than for girls (Rothbaum \& Weisz, 1994), and the greater the proportion of girls in study samples, the weaker the associations between corporal punishment and child aggression have been (Gershoff, 2002). Thus, child gender differences 
must be considered in a study of this kind, although how the proposed model may differ by gender is exploratory. Findings will enrich the discussion of the differing developmental influences on the trajectories of boys' and girls' problem behavior that were highlighted in Keenan and Shaw's (1997) cogent review.

\section{Parent Gender: The Previously Ignored Role of Paternal Report and Influence}

Whereas child gender differences are often considered in developmental research, differences by parent gender are less frequently studied. Generally, fathers' influences on child outcomes have been ignored in the literature (Phares \& Compas, 1992). Although associations between parental behaviors and child externalizing symptoms generally are stronger for mothers than for fathers (Rothbaum \& Weisz, 1994), several studies have documented the importance of paternal influences on child behavior problems (e.g., DeKlyen, Biernbaum, Speltz, \& Greenberg, 1998; Denham et al., 2000). Numerous studies have demonstrated that mothers and fathers differ on choice, frequency, and intensity of disciplinary interventions (e.g., Fagot \& Hagan, 1991; Nobes, Smith, Upton, \& Heverin, 1999; Straus \& Stewart, 1999). For these reasons, the influences of both maternal and paternal discipline on moral regulation and externalizing behavior problems will be examined.

\section{The Present Study}

To review, moral regulation and externalizing behavior problems are related, but conceptually distinct phenomena in early childhood that were found to be negatively associated in previous analyses with this sample (Olson, Kerr, et al., 2004). Discipline practices have been separately associated with children's moral regulation and externalizing problems (Denham et al., 2000; Kochanska, 1993), but these links have not been examined simultaneously. We propose that parental discipline and child externalizing symptoms are interrelated and that variations in child moral regulation mediate this relationship. We tested this model in a sample of 3.5-year-old children evidencing a range of levels of risk for school-age behavior problems.

Consistent with previous research, we predicted that preschoolers whose parents use more inductive techniques and warm responsiveness and place less emphasis on physical punishment would show fewer externalizing problems (e.g., Denham et al., 2000; Gershoff, 2002). Second, and also consistent with the literature, parental use of induction and warm responsiveness and less frequent physi- cal punishment were hypothesized to be associated with higher levels of child moral regulation (Hoffman, 1983; Kochanska, 1993; Kochanska \& Aksan, 1995; Kochanska $\&$ Murray, 2000). Related to these questions, we also investigated whether induction, warmth, and physical punishment were overlapping dimensions of a particular parental discipline style or were independently related to child adjustment.

Third, we predicted that a mediation model would be supported. That is, we expected that the magnitude of hypothesized associations between parent discipline behaviors and child externalizing behavior problems would be reduced significantly once we accounted for the proposed mediator: individual differences in child moral regulation.

Our fourth goal was to examine whether associations among discipline, moral regulation, and externalizing problems, and the proposed mediation model would be differentially patterned for boys and girls. Finally, we sought to identify differences in how maternal and paternal disciplinary behaviors relate to levels of children's moral regulation and behavior problems.

\section{METHOD}

\section{Participants}

Participants were 238 3.5-year-old children (116 girls; age range $=32-45$ months, $M=41.4$ months, $S D=$ 2.0 months) and their parents who were part of an ongoing longitudinal study of young children at risk for school-age conduct problems (Olson \& Sameroff, 1997). Children were recruited to represent the full range of externalizing symptom severity on the Child Behavior Checklist/23 (Achenbach, 1992), with an oversampling of children in the upper range of the Externalizing Problems scale; 21 children $(9 \%)$ scored in the clinical range $(T \geq 70)$ on CBCL/2-3 and/or CTRF/2-5. Families were recruited from local and regional preschool centers, newspaper ads, and pediatrician referrals. We excluded children for whom severe individual or familial risk factors might overwhelm the subtler effects in question (e.g., those with serious chronic health problems or cognitive impairments).

A subsample of fathers agreed to complete questionnaires $(N=158) ; 122$ fathers participated in the home interview. A majority of participating children attended preschool at the time of the parental assessments. Most preschool teachers who were asked to contribute ratings of children's behavioral adjustment agreed $(N=189)$.

Families were representative of the local population. The majority of children were of European American heritage $(86 \%)$, and most others were identified as African 
American (5\%) or biracial (8\%). Most mothers were married $(89 \%), 3 \%$ were living with a partner, $5 \%$ were single (never married), and 3\% were divorced. Fifty-five percent of mothers worked outside the home. Nineteen percent of mothers and $24 \%$ of fathers had received high school education only; $46 \%$ of mothers and $34 \%$ of fathers had completed 4 years of college only; and $35 \%$ of mothers and $42 \%$ of fathers had completed additional graduate or professional training. The median annual family income was $\$ 52,000$, ranging from $\$ 20,000$ to over $\$ 100,000$.

\section{Procedures}

\section{Parent and Teacher Reports}

Mothers and participating fathers were interviewed separately in their homes by a female social worker. Parents then completed a packet of questionnaires. Families were paid for their involvement. Preschool teachers who provided ratings of children's behavior problems were given gift certificates for their participation.

\section{Laboratory Assessment}

Most children $(N=227)$ participated in a 4-hr assessment held at a local preschool on a Saturday morning. Some children did not complete the lab because of scheduling problems or pronounced difficulty with parental separation. After building rapport with the children, graduate student examiners administered a series of cognitive and self-regulatory tests on the basis of the toddler-age behavioral battery by Kochanska et al. (1996). For a full description of the tasks used with this sample, see Olson, Sameroff, et al. (2004).

\section{Measures}

\section{Externalizing Behavior Problems}

Mothers and fathers independently completed the Child Behavior Checklist/Ages 2-3 (CBCL/2-3; Achenbach, 1992), a measure of behavioral and emotional problems. Respondents rate the child on 99 items that describe her/his behavior over the previous 2 months using a 3-point scale (" 2 " = very true or often true of the child; " 1 " = somewhat or sometimes true; " $0 "=$ not true). There are two broadband, factor-analytically derived dimensions of problem behavior, Internalizing (25 items on Anxious/Depressed and Withdrawn subscales) and Externalizing (26 items on Aggressive Behavior and Destructive Behavior subscales). Achenbach (1992) reported high test-retest reliability for the Externalizing Problems scale $(r=.84)$.

Teachers completed the Caregiver/Teacher Report Form, Ages 2-5 (CTRF/2-5; Achenbach, 1997). The behavior problem items are identical to those of CBCL/2-3. Achenbach derived broad Internalizing and Externalizing scales, with subscale components that differed somewhat from those of CBCL (e.g., the Externalizing Problems scale was defined by Aggressive Behavior and Attention Problems). Achenbach reports high test-retest and crossinformant reliability for the Externalizing scale $(r \mathrm{~s}=.90$ and .72 , respectively).

Sums of items on the Externalizing scale were used to represent each informant's report of children's externalizing problem severity. It has been argued that discrepant accounts of children's behavioral functioning by different informants may represent true differences across contexts rather than unreliable ratings (e.g., Achenbach \& Rescorla, 2001; Hinshaw \& Nigg, 1999). Additionally, children who evidence externalizing behaviors across multiple contexts appear to be at added risk for stable problems (reviewed in Campbell et al., 2000; Schachar, 1991). Thus, to obtain an assessment of children's externalizing problems across multiple, diverse contexts, we created an aggregate score by averaging $z$ scores of all available informants' externalizing behavior problem scores $(\alpha=.63)$. For $93 \%$ of the sample, reports of externalizing behavior problems were available from at least two informants.

\section{Gift Task}

A gift task was administered during the laboratory assessment as a measure of rule-following and resistance to temptation. Each child was told that s/he would receive a prize, but that s/he needed to wait until the examiner wrapped it. The child was told to face away from the examiner and "not to peek" for $60 \mathrm{~s}$ whereas the prize was noisily wrapped. The child was reminded up to two times during the task not to peek if s/he did so. After wrapping the prize, the examiner placed it within the child's reach and asked her/him to sit facing the prize. The examiner asked the child not to touch the prize whereas s/he looked for a bow for $120 \mathrm{~s}$. If the child touched the prize, s/he was told up to two times that the game was not over yet. The number of times the child peeked while the prize was wrapped and the number of times s/he touched the gift while the examiner looked for the bow were tallied. Fifteen test administrations were videotaped and independently scored for agreement on tallies of "peeks" and "touches" ( $\kappa \mathrm{s}=.92$ and .95 , respectively). A summary score was created by averaging $z$ scores for these tallies. After completing a log transformation to lessen positive skewness, 
the variable was reverse scored; higher scores indicated greater restraint.

\section{Moral Regulation}

Mothers' and fathers' ratings on the broadband Active Moral Vigilance/Regulation scale of Kochanska et al.'s (1994) My Child questionnaire were used to assess early conscience ( $\alpha \mathrm{s}=.90$ and .91 , respectively). The Moral Regulation scale consists of 43 items and is defined as the ability to refrain from wrongdoing through behavioral control. Sample items include "likely to try a prohibited but attractive activity when alone," "seems compelled to tell parents when she or he does something wrong," and "gets upset when a guest breaks household rules." Parents rate each item on a scale from 1 (untrue, not at all characteristic of my child) to 7 (extremely true, very characteristic of my child). Analyses by Kochanska et al. revealed that My Child has good psychometric properties and moderate relations with independent assessments of children's moral behavior in a laboratory setting. Responses were reverse scored when necessary and then averaged to create total scores, such that higher scores were indicative of higher levels of Moral Regulation. A second-order factor analysis with this sample replicated this broadband dimension of conscience found by Kochanska et al. and revealed that mother and father reports of Moral Regulation contribute uniquely to variations in externalizing behavior problem severity (Olson, Kerr, et al., 2004). Following the rationale for creating an aggregate externalizing score, an aggregate measure of Moral Regulation was computed by averaging $z$ scores on maternal and paternal reports of Moral Regulation and restraint on the gift task $(\alpha=.52)$.

\section{Discipline and Parenting Behaviors}

Dodge, Pettit, and Bates' (1994) Harshness of Discipline scale was used during individual interviews with mothers and fathers to assess the frequency with which each parent had physically disciplined their child (e.g., spank, grab, shake) during the last 3 months. Possible responses were "never" (value $=0$ ), "once/month" (1), "once/week" (2), "daily" (3), and "several times daily" (4); when parents circled two adjacent responses, the value was averaged (e.g., $1.5=$ between once/month and once/ week). Parents' reports of their own use of physical discipline were relatively low in frequency. Yet, research suggests that the amount of physical punishment that children experience from both parents combined is considerably greater than from either parent alone (Nobes \& Smith, 1997). For these reasons, we adapted this measure by creating a rank-order scale to measure the frequency with which each parent reported that their child received physical punishment from either parent. Thus, the lowest rank $($ rank $=0)$ was assigned to children who received no physical punishment from either their mother or father (scores $=$ 0 and 0 ). According to mothers, $23 \%$ of the sample was in this group. Children assigned the next lowest rank (rank $=$ 1) had received physical punishment from one parent between "once per month" and "never," and none of this type of discipline from their other parent (scores $=0.5$ and 0 ). The rank of 2 was assigned to children who received scores of 0.5 and 0.5 . On the basis of the responses in this sample, 36 rankings were made. Children who reportedly experienced physical punishment several times daily from both parents received the highest rank.

For each parent, two other theoretically important domains of parenting and discipline style were derived using the parent-completed Parenting Dimensions Inventory (PDI; Power, Kobayashi-Winata, \& Kelley, 1992). The Reasoning and Reminding subscales of PDI were considered dimensions of an inductive discipline style and positively correlated for mothers, $r(232)=.67, p<.001$, and fathers, $r(146)=.57, p<.001$. Measures of maternal and paternal induction were created by averaging $z$ scores on these two subscales (alphas for maternal and paternal induction were .75 and .85 , respectively). Similarly, the Nurturance and Responsiveness subscales were theoretically related dimensions of parental warmth and were positively correlated for both mothers, $r(232)=.47$, $p<.001$, and fathers, $r(148)=.48, p<.001 . z$ Scores of these two subscales were averaged to form measures of both maternal and paternal warmth $(\alpha \mathrm{s}=.73$ and .80 , respectively).

\section{RESULTS}

\section{Preliminary Analyses}

Descriptive statistics on study measures are reported in Table I. To better facilitate interpretation, the table describes component scales of the gift task (frequencies of two types of violations: peeking and touching the gift) separately rather than the transformed summary measure. Also, measures of parental induction and warmth that are listed are based on averaged component subscales rather than on averaged $z$ scores of subscales (because no differences would be found between scales based on $z$ scores).

\section{Associations Among Child Behaviors}

Maternal ratings of Moral Regulation were positively related to paternal ratings, $r(149)=.45, p<.001$, and 
Table I. Means and Standard Deviations on Variables of Central Interest

\begin{tabular}{lccc}
\hline & Total & Girls & Boys \\
\hline Child behavior measures & & & \\
$\quad$ Externalizing behaviors & & & \\
$\quad$ Mother & $11.6(7.4)$ & $11.2(7.2)$ & $11.9(7.5)$ \\
$\quad$ Father & $10.7(6.7)$ & $9.4(6.1)$ & $12.0(7.1)$ \\
$\quad$ Teacher & $10.2(12.7)$ & $7.7(10.3)$ & $12.6(14.2)$ \\
Moral regulation & & & \\
$\quad$ Mother & $4.2(0.6)$ & $4.3(0.6)$ & $4.1(0.6)$ \\
$\quad$ Father & $4.0(0.6)$ & $4.1(0.6)$ & $4.0(0.6)$ \\
Gift task rule violations & & & \\
$\quad$ \# Of peeks & $2.9(4.4)$ & $1.7(3.6)$ & $3.8(4.8)$ \\
$\quad$ \# Of touches & $1.2(2.7)$ & $0.8(2.0)$ & $1.5(3.1)$ \\
Parental discipline measures & & & \\
Physical punishment & & & \\
$\quad$ Mother & $6.3(6.8)$ & $5.4(6.1)$ & $7.1(7.4)$ \\
$\quad$ Father & $6.8(7.1)$ & $6.4(6.8)$ & $7.2(7.4)$ \\
Induction & & & \\
$\quad$ Mother & $2.0(0.4)$ & $2.0(0.4)$ & $2.0(0.4)$ \\
$\quad$ Father & $1.9(0.4)$ & $1.9(0.5)$ & $1.9(0.3)$ \\
Warmth & & & \\
$\quad$ Mother & $5.4(0.5)$ & $5.5(0.4)$ & $5.4(0.5)$ \\
Father & $5.2(0.5)$ & $5.3(0.5)$ & $5.2(0.5)$ \\
\hline
\end{tabular}

Note. $N$ s ranged from 233 to 238 for mother report measures and from 122 to 158 for father report measures; $N$ s for teacher reports and the gift task were 189 and 227 , respectively.

to restraint on the gift task, $r(224)=.23, p<.005$. Fathers' ratings of Moral Regulation were not related to gift task scores. As reported in Olson, Sameroff, et al. (2004), behavior problem ratings from mothers, fathers, and teachers were significantly intercorrelated, ranging from, $r(187)=.16, p<.05$, between mother and teacher reports to, $r(157)=.46, p<.001$, between mother and father reports.

As shown in Table II, both maternal and paternal reports of Moral Regulation were negatively associated with externalizing behavior problems as reported by mothers, fathers, and teachers (as reported in Olson, Kerr, et al.,

Table II. Correlations Among Indicators of Moral Regulation and Externalizing Behavior Problems

\begin{tabular}{lllll}
\hline & \multicolumn{3}{c}{ Externalizing behavior problems } \\
\cline { 2 - 5 } Moral regulation & Mother & Father & Teacher & EBP aggregate \\
\hline Mother report & $-.46^{* * *}$ & $-.37^{* * *}$ & $-.21^{* *}$ & $-.43^{* * *}$ \\
Father report & $-.26^{* *}$ & $-.41^{* * *}$ & $-.30^{* *}$ & $-.42^{* * *}$ \\
Gift task & -.05 & $-.24^{* *}$ & $-.27^{* * *}$ & $-.21^{* *}$ \\
MR aggregate & $-.35^{* * *}$ & $-.46^{* * *}$ & $-.33^{* * *}$ & $-.45^{* * *}$ \\
\hline
\end{tabular}

Note. Ns ranged from 123 (between teachers and fathers) to 227 (between mother report and the gift task). $\mathrm{MR}=$ Moral Regulation; $\mathrm{EBP}=$ Externalizing Behavior Problems. Scores on the gift task were reverse coded so that higher scores indicate greater behavioral restraint. ${ }^{* *} p<.01{ }^{* * *} p<.001$.
2004). Restraint on the gift task also was negatively associated with externalizing behaviors reported by fathers and teachers. Not surprisingly, the aggregate measures of Moral Regulation and externalizing behavior problems were negatively related.

\section{Associations Among Measures of Parental Discipline}

Maternal reports of induction and warmth were positively correlated, $r(232)=.34, p<.001$, and negatively related to maternal reports of physical discipline, $r(232)=$ -.31 and -.23 , respectively, both $p<.001$. By paternal report, induction was positively correlated with warmth, $r(146)=.27, p<.01$, and negatively associated with frequency of physical discipline, $r(104)=-.28, p<.01$. Cross-informant associations revealed that mothers and fathers agreed moderately on the frequency with which their children received physical punishment, $r(121)=$ $.40, p<.001$, and on their use of induction, $r(145)=.33$, $p<.001$.

\section{Comparisons Between Subsamples With Different Levels of Father and Teacher Participation}

The subsample of participants for whom maternal and paternal data were available was compared to the subsample with mother participation only using MANOVAs. There were no significant differences between these groups on study variables. Participant families with and without teacher data were compared on study variables using MANOVAs. No differences existed on parental measures of externalizing behavior problems or Moral Regulation. However, children for whom teachers contributed behavioral ratings showed more restraint on the gift task than did those without teacher reports, $t(225)=2.10, p<.05$.

\section{Child and Parent Gender Differences on Key Measures}

\section{Child Gender Differences on Levels of Parental Discipline and Child Behaviors}

To determine whether gender differences existed on any of the dependent or independent measures, four MANOVAs were conducted, each with child gender as the independent variable. First, when mother, father, and preschool teacher reports of externalizing behavior problems were entered as dependent variables, a significant effect of gender was obtained, $F(3,126)=3.08, p<$ .05 . According to fathers, $t(156)=2.48, p<.05$, and 
teachers, $t(187)=2.68, p<.01$, boys showed more problem behaviors than did girls. Second, when mother and father reports of Moral Regulation and performance on the gift task were entered as dependent measures, there was a main effect of child gender, $F(3,143)=2.70, p<$ .05. Girls evidenced higher levels of Moral Regulation according to mother report, $t(232)=2.25, p<.05$, and showed more restraint on the gift task, $t(225)=4.24$, $p<.001$, than did boys. There were no differences between boys and girls when parental reports of physical punishment, induction, and warmth were considered as dependent variables (separate MANOVAs for mothers and fathers).

\section{Differences in Parental Discipline by Parent Gender}

Next, we examined whether mothers and fathers differed on their reports of discipline methods and whether any such differences depended on child gender. In separate, repeated measures ANOVAs, each of the parental discipline measures was treated as a within-participants measure with two levels (maternal and paternal reports); the Parent Gender $\times$ Child Gender interaction also was entered. The within-participants effects of parent gen- der were significant for both induction, $F(1,145)=7.5$, $p<.01$, and warmth, $F(1,146)=8.8, p<.01$. Mothers endorsed higher levels of induction and warmth than did fathers. The interaction was nonsignificant, suggesting that these differences did not depend on child gender. There were no significant effects of parent gender, alone or in interaction with child gender, on reports of the frequency with which children received physical punishment.

\section{Relationships Between Parental Discipline and Child Behavioral Measures}

Intercorrelations between parental discipline and child behaviors were computed separately for boys and girls. As shown in Table III, associations were in the hypothesized directions, but generally were significant for boys only. The frequency of boys' experience of physical punishment tended to be negatively associated with Moral Regulation and positively related to externalizing problems. Among boys, parental induction and warmth generally related positively to Moral Regulation and negatively to externalizing behavior problems. Paternal discipline measures often were associated with other informants' ratings of boys' behaviors, and with restraint on

Table III. Zero-Order Correlations Between Parental Discipline Measures and Reports of Child Moral Regulation and Externalizing Behavior Problems

\begin{tabular}{|c|c|c|c|c|c|c|}
\hline \multirow[b]{2}{*}{ Discipline style } & \multicolumn{3}{|c|}{ Moral regulation } & \multicolumn{3}{|c|}{ Externalizing behavior problems } \\
\hline & Mother & Father & Gift task & Mother & Father & Teache \\
\hline \multicolumn{7}{|l|}{ Boys } \\
\hline \multicolumn{7}{|l|}{ Physical punishment } \\
\hline Mother & $-.35^{* * *}$ & -.05 & -.15 & $.37^{* * * *}$ & .16 & .14 \\
\hline Father & $-.32^{*}$ & -.14 & $-.38^{* *}$ & $.27^{*}$ & $.43^{* *}$ & $.26^{\dagger}$ \\
\hline \multicolumn{7}{|l|}{ Induction } \\
\hline Mother & $.32^{* * *}$ & .10 & .12 & $-.39^{* * *}$ & $-.27^{*}$ & -.04 \\
\hline Father & $.33^{* *}$ & $.26^{*}$ & $.38^{* *}$ & -.15 & $-.33^{* *}$ & -.17 \\
\hline \multicolumn{7}{|l|}{ Warmth } \\
\hline Mother & $.24^{* *}$ & -.05 & .04 & $-.29^{* *}$ & .04 & $-.18^{\dagger}$ \\
\hline Father & $.18^{\dagger}$ & $.38^{* *}$ & .14 & $-.26^{*}$ & $-.39^{* *}$ & $-.46^{* * *}$ \\
\hline \multicolumn{7}{|l|}{ Girls } \\
\hline \multicolumn{7}{|l|}{ Physical punishment } \\
\hline Mother & -.14 & -.12 & -.08 & $.16^{\dagger}$ & .08 & $.18^{\dagger}$ \\
\hline Father & -.10 & -.11 & -.02 & .06 & .08 & $.27^{\dagger}$ \\
\hline \multicolumn{7}{|l|}{ Induction } \\
\hline Mother & .14 & .09 & -.09 & -.08 & -.07 & $.19^{\dagger}$ \\
\hline Father & -.04 & .00 & -.07 & -.06 & -.05 & .10 \\
\hline \multicolumn{7}{|l|}{ Warmth } \\
\hline Mother & .13 & .03 & -.07 & -.14 & .04 & -.16 \\
\hline Father & .06 & $.24^{*}$ & .06 & -.10 & $-.21^{\dagger}$ & -.06 \\
\hline
\end{tabular}

Note. The table lists two-tailed significance levels for Pearson correlation coefficients. Pairwise $N \mathrm{~s}$ for maternal discipline variables ranged from 74 to 122 for boys and from 75 to 114 for girls; Pairwise $N$ s for paternal discipline variables ranged from 51 to 75 for boys and from 41 to 74 for girls.

${ }^{\dagger} p<.10 .{ }^{*} p<.05 .{ }^{* *} p<.01 .{ }^{* * *} p<.001$. 
the gift task. In contrast, mothers' discipline ratings only related to maternal ratings of boys' Moral Regulation and externalizing behavior problems, with the exception of a significant association between maternal induction and paternal ratings of externalizing problems. Among girls, the only significant relationship was between warmth and higher levels of Moral Regulation, both by paternal report.

When items on CBCL and CTRF related to defiance, cheating, and lying were omitted from measures of externalizing, the magnitude of the relationships among behavior problems and measures of Moral Regulation, restraint on gift task, and parental discipline styles did not change appreciably. Thus, the standard, more psychometrically sound measures of externalizing symptoms were used in all analyses.

Next, multiple regression analyses were conducted to examine the potentially independent contributions of parents' use of physical punishment and induction and levels of parental warmth to variability in ratings of boys' externalizing behavior problems and Moral Regulation. Regressions were run only for those child behavioral outcomes that had been shown to have significant bivariate relationships with one or more of the parental discipline measures.

Table IV presents the results of regressions in which the three maternal discipline variables predicted boys' externalizing behavior problems and Moral Regulation. In the first regression, maternal discipline significantly predicted maternal reports of boys' externalizing behavior problems. Specifically, lower levels of induction and more frequent use of physical punishment independently predicted greater levels of boys' externalizing behavior prob-

Table IV. Boys' Externalizing Behavior Problems and Moral Regulation Regressed on Maternal Discipline Measures

\begin{tabular}{|c|c|c|c|}
\hline & $B$ & $S E(B)$ & $\beta$ \\
\hline \multicolumn{4}{|c|}{ Model 1. Criterion: Mother-reported behavior problems (CBCL/2-3) } \\
\hline Physical punishment & 0.26 & 0.09 & $.26^{* *}$ \\
\hline Induction & -1.05 & 0.37 & $-.26^{* *}$ \\
\hline Warmth & -0.50 & 0.37 & -.12 \\
\hline \multicolumn{4}{|c|}{ Model 2. Criterion: Father-reported behavior problems (CBCL/2-3) } \\
\hline Physical punishment & 0.11 & 0.11 & .12 \\
\hline Induction & -1.19 & 0.45 & $-.32^{*}$ \\
\hline Warmth & 0.75 & 0.43 & $.21^{\dagger}$ \\
\hline \multicolumn{4}{|c|}{ Model 3. Criterion: Mother-reported moral regulation } \\
\hline Physical punishment & -0.02 & 0.01 & $-.28^{* *}$ \\
\hline Induction & 0.07 & 0.03 & $.20^{*}$ \\
\hline Warmth & 0.03 & 0.03 & .10 \\
\hline
\end{tabular}

Note. The significance levels of the full models were as follows:

1. $F(3,117)=11.66, p<.001$; Adj. $R^{2}=.21$.

2. $F(3,75)=3.21, p<.05$; Adj. $R^{2}=.08$.

3. $F(3,116)=8.95, p<.001 ;$ Adj. $R^{2}=.17$.

${ }^{\dagger} p<.10 .{ }^{*} p<.05 .{ }^{* *} p<.01 .^{* * *} p<.001$. lems. Second, in a separate regression, mothers' discipline also predicted paternal reports of boys' externalizing behavior problems; lower levels of maternal induction and (marginally significantly) warmth were associated with higher behavior problems. Third, maternal discipline significantly predicted mother reports of boys' Moral Regulation. Maternal reports of less induction and more frequent experience of physical punishment were independently associated with lower levels of Moral Regulation.

Table $\mathrm{V}$ shows the results of regressions in which the three paternal discipline measures were entered as predictors of boys' externalizing behavior problems and Moral Regulation. First, father discipline significantly predicted maternal reports of boys' externalizing behavior problems. However, the only independent effect was a marginally significant relationship between less warmth and greater levels of boys' externalizing problems. In a second regression, lower levels of paternal induction and warmth were significantly and independently related to father reports of boys' externalizing symptoms. Third, low paternal warmth was a significant, independent predictor of greater behavior problems as reported by teachers. Fourth, although previous analyses showed that paternal discipline measures were correlated with mother and father reports of Moral Regulation, regression analyses were not significant. Finally, greater paternal induction was a unique predictor of higher levels of boys' restraint on the gift task.

\section{Moral Regulation as a Potential Mediator of the Relationship Between Parental Discipline and Boys' Externalizing Behavior Problems}

Baron and Kenny's (1986) guidelines were followed for testing whether Moral Regulation mediated the relationships between parental discipline variables and boys' externalizing problems. This was deemed appropriate, given that parental discipline variables were associated with ratings of both Moral Regulation and externalizing behavior problems among boys, and associations existed between Moral Regulation and externalizing problems. Several steps were taken to simplify analyses. First, aggregate measures of Moral Regulation and externalizing behavior problems were used to better represent children's behavior in multiple contexts (Campbell et al., 2000), lessen effects attributable to shared variance, and reduce the number of models run. Second, models were run only for those children for whom mother and father data were available to ensure that any differences in whether mediation occurred depended on relationships among variables rather than on the particular subsample being considered. 
Table V. Boys' Externalizing Behavior Problems and Moral Regulation Regressed on Paternal Discipline Measures

\begin{tabular}{|c|c|c|c|}
\hline & $B$ & $S E(B)$ & $\beta$ \\
\hline \multicolumn{4}{|c|}{ Model 1. Criterion: Mother-reported behavior problems (CBCL/2-3) } \\
\hline Physical punishment & 0.17 & 0.16 & .16 \\
\hline Induction & -0.27 & 0.84 & -.05 \\
\hline Warmth & -1.19 & 0.61 & -.28 \\
\hline \multicolumn{4}{|c|}{ Model 2. Criterion: Father-reported behavior problems (CBCL/2-3) } \\
\hline Physical punishment & 0.18 & 0.12 & .19 \\
\hline Induction & -1.36 & 0.63 & $-.27^{*}$ \\
\hline Warmth & -1.33 & 0.46 & $-.36^{* *}$ \\
\hline \multicolumn{4}{|c|}{ Model 3. Criterion: Teacher-reported behavior problems (CTRF/2-5) } \\
\hline Physical punishment & -0.19 & 0.37 & -.09 \\
\hline Induction & -1.58 & 1.81 & -.15 \\
\hline Warmth & -3.25 & 1.25 & $-.42^{*}$ \\
\hline \multicolumn{4}{|c|}{ Model 4. Criterion: Restraint on gift task } \\
\hline Physical punishment & 0.01 & 0.01 & -.14 \\
\hline Induction & 0.08 & 0.03 & $.38^{*}$ \\
\hline Warmth & 0.00 & 0.02 & -.01 \\
\hline
\end{tabular}

Note. The significance levels of the full models were as follows:

1. $F(3,48)=2.84, p<.05$; Adj. $R^{2}=.10$.

2. $F(3,48)=9.80, p<.001 ;$ Adj. $R^{2}=.34$.

3. $F(3,39)=3.29, p<.05 ;$ Adj. $R^{2}=.14$.

4. $F(3,48)=4.21, p<.05 ;$ Adj. $R^{2}=.16$.

${ }^{\dagger} p<.10 .{ }^{*} p<.05 .{ }^{* *} p<.01 .{ }^{* * *} p<.001$.

Third, mediation was tested for individual discipline variables to simplify the tests for the potential indirect effects of each predictor on externalizing via Moral Regulation.

We conducted Sobel tests to determine whether potential indirect effects of each discipline variable on externalizing behavior problems through Moral Regulation were significantly different from zero. This test has been shown to be equivalent to the test for the difference in regression coefficients for the independent variable before and after entering the proposed mediator into the model (Judd \& Kenny, 1981; MacKinnon, Warsi, \& Dwyer, 1995), and also allows one to test the significance of a par- tial mediation effect. Partial mediation may suggest that both direct and indirect relationships between the independent and the dependent variables exist. Such an effect may be indicated when the regression coefficient for the independent variable is reduced significantly when the mediator is in the model, but remains significant. An online resource provided by Preacher and Leonardelli (2001) was used to calculate Sobel tests (Goodman I type was most conservative).

Table VI summarizes the results of the progression of tests of mediation for the discipline variables, except maternal warmth, which was not significantly related to

Table VI. Summary of Results of Mediation Analyses

\begin{tabular}{lcccc}
\hline \multicolumn{1}{c}{ Discipline variable } & $\begin{array}{c}\text { Model } 1 \beta \\
\text { predicting MR }\end{array}$ & $\begin{array}{c}\text { Model 2 } \beta \\
\text { predicting EBP }\end{array}$ & $\begin{array}{c}\text { Model 3 } \beta \text { predicting } \\
\text { EBP, controlling for MR }\end{array}$ & $\begin{array}{c}\text { Model 2-Model 3 } \\
\text { change statistic }^{a}\end{array}$ \\
\hline Maternal physical punishment $(N=80)$ & $-.24^{*}$ & $.29^{* *}$ & $.17^{\dagger}$ & $1.97^{*}$ \\
Maternal induction $(N=79)$ & $.24^{*}$ & $-.40^{* * *}$ & $-.29^{* *}$ & $-1.94^{\dagger}$ \\
Maternal warmth $(N=79)$ & .12 & $-.24^{*}$ & $-.18^{\dagger}$ & $n a$ \\
Paternal physical punishment $(N=54)$ & $-.42^{* *}$ & $.42^{* *}$ & $.24^{\dagger}$ & $2.26^{*}$ \\
Paternal induction $(N=74)$ & $.47^{* * *}$ & $-.28^{*}$ & -.02 & $-3.36^{* * *}$ \\
Paternal warmth $(N=75)$ & $.33^{* *}$ & $-.46^{* * *}$ & $-.31^{* *}$ & $-2.51^{*}$ \\
\hline
\end{tabular}

Note. Betas $(\beta \mathrm{s})$ from three regression models were used to test whether each discipline variable predicts boys' (1) moral regulation, (2) externalizing behavior problems, and (3) externalizing behavior problems after controlling for moral regulation. Aggregate child outcomes were used. MR $=$ Moral Regulation; EBP $=$ Externalizing Behavior Problems.

${ }^{a}$ Each Sobel statistic tests whether the indirect effect of the discipline variable on EBP via MR is significantly different from zero.

${ }^{\dagger} p<.10 .{ }^{*} p<.05 .{ }^{* *} p<.01 .{ }^{* * *} p<.001$. 
Moral Regulation. Four of the five Sobel test statistics were significant (ranging in absolute value from 1.97 to 3.36, all $p<.05$ ). Notably, the ability to predict externalizing behavior problems from paternal induction approached zero when Moral Regulation was controlled. Thus, Moral Regulation fully mediated the association between paternal induction and boys' externalizing problems and partially mediated associations that parental physical punishment and paternal warmth had with boys' externalizing problems.

\section{DISCUSSION}

A large body of prior research has shown that parental disciplinary behaviors are associated with variations in child externalizing problems (e.g., Denham et al., 2000; Gershoff, 2002). However, the processes by which parenting practices may influence the development of externalizing problems are not clearly understood. Some scholars have suggested that parenting behaviors are linked to the development of self-regulation and internalized standards of conduct (e.g., Hoffman, 1983; Kochanska \& Aksan, 1995), which in turn are thought to underlie children's capacity to refrain from disruptive and/or aggressive behavior (e.g., Gardner \& Ward, 2000). Yet, to date there have been no empirical studies integrating the relationships among parental disciplinary practices, child conscience, and child externalizing problems. Hence, we evaluated the hypothesis that associations between parental discipline practices and child externalizing behavior problems were mediated by individual differences in moral regulation in a sample of 3.5-year-old children at elevated risk for school-age externalizing problems.

\section{Relations Among Parenting Practices, Moral Regulation, and Externalizing Behavior Problems}

We hypothesized that parents who more frequently used physical punishment, and who endorsed lower levels of warmth and inductive discipline, would have children with relatively low levels of moral regulation and high levels of externalizing problems. Our hypotheses were confirmed for boys only, a pattern that will be discussed in detail. Although relationships were strongest within informant, parental discipline had cross-contextual linkages with boys' behavioral functioning, as well as clear associations with aggregate measures of moral regulation and externalizing behavior. Results for boys are consistent with theories that children's conscience development is facilitated by parental discipline strategies involving warmth, the use of induction, and a de-emphasis on power-assertive techniques such as physical punishment (Hoffman, 1983; Hoffman \& Saltzstein, 1967; Kochanska \& Aksan 1995). These findings also converge with prior research linking less corporal punishment and greater warmth and induction to fewer externalizing symptoms (e.g., Denham et al., 2000; Gershoff, 2002).

Another important contribution of this study was the examination of parental use of induction, warmth, and physical punishment as unique correlates of child outcomes, given that these discipline styles have been found to co-occur in this and other samples. Results suggested that maternal reports of induction and physical punishment generally had unique relationships with boys' adjustment, as did paternal induction and warmth. In contrast, results indicated that maternal warmth and paternal physical punishment did not contribute incrementally to individual differences in boys' moral regulation or externalizing behaviors. These findings support theoretical distinctions that have been made among particular types of parental interventions and their differential implications for child conscience and conduct problems (e.g., Gershoff, 2002; Grusec \& Goodnow, 1994; Hoffman \& Saltzstein, 1967).

\section{Direct and Indirect Links Between Discipline and Externalizing: The Role of Moral Regulation}

The relationship between paternal induction and boys' externalizing problems was mediated by moral regulation. That is, fathers' use of induction was positively related to moral regulation, but not to externalizing behavior problems after accounting for this component of early conscience. In addition, associations between other forms of parental discipline (except maternal warmth) and boys' externalizing behavior problems were partially mediated by moral regulation. These partial mediation effects are consistent with a model wherein parental physical discipline, paternal warmth, and maternal induction may have direct effects on externalizing problems, as well as indirect influence on externalizing through effects on moral regulation.

These findings raise questions about the degree to which moral regulation and externalizing behavior problems represent overlapping constructs. The most serious threat to the validity of the proposed model would occur if, apart from any theoretical distinctions between the constructs, behavioral evidence of low moral regulation and greater externalizing problems are experienced by parents and other caregivers simply as one dimension of "hard-to-manage" behaviors. Similar concerns have been raised in previous research relating child temperament to adjustment (e.g., Olson, Bates, Sandy, \& Lanthier, 2000; 
Rothbart \& Bates, 1998). However, a number of steps were taken to address this concern. First, inspection of items on the Kochanska et al. (1994) and the Achenbach (1992, 1997) scales revealed that these scales sample distinct domains of child behavior and, again, the constructs are only moderately correlated. Thus, moral regulation does not appear to be a simple "proxy" for externalizing problems. Second, when items with the greatest likelihood of conceptual overlap were deleted from the measures of externalizing, relations between externalizing and both moral regulation and parental discipline remained stable. Third, aggregate measures of moral regulation and externalizing behavior problems were created using multiple sources of information, a strategy that lessens the likelihood that associations hinge on perceptions of a particular informant. Furthermore, maternal ratings of moral regulation were better predictors of teachers' ratings of child externalizing than were maternal ratings of externalizing. Paternal ratings of moral regulation also had connections to behavior problems across informant contexts. Although not tested formally, these findings are consistent with a view of moral regulation as a quality of children's functioning that is stable across situations, as would be expected if the capacity was rooted in temperament and internalization.

Next, even if moral regulation and externalizing behavior problems represent different constructs that are modestly intercorrelated, there remains a significant analytic concern. That is, when testing mediation, even a modest amount of overlap between the mediator and the dependent variable may diminish a comparably modest association between independent and dependent variables to the point at which mediation seems apparent. Again, in this study, the aggregation of multiple sources of information about moral regulation and externalizing behavior problems should lessen these concerns. That is, the degree to which relationships among measures are driven by error in, for example, individual informants' biases or response styles should be lessened or cancelled out using aggregate scores. Additionally, we used a more formal test of mediation to determine whether the strength of predictors of externalizing diminished significantly, rather than just became nonsignificant. Table VI reflects the sizeable reductions in the degree to which discipline behaviors predicted boys' externalizing problems after accounting for moral regulation. Still, the model awaits replication using additional sources of information about parental behaviors and children's functioning to supplement our use of parent reports.

Findings supporting indirect pathways between parental discipline and externalizing behavior problems via moral regulation have several implications for the proposed theoretical model. First, results are consistent with theories that physical discipline influences the expression of behavior problems, in part, through detrimental effects on the developing conscience. For example, Hoffman (1983) and Kochanska (1997) suggest that harsh, powerassertive discipline may overarouse children during discipline encounters and inhibit their processing of parental messages about acceptable behavior. Physical discipline also may cause children to attribute the causes of the acceptable behavior to external rather than internal factors (e.g., Dix \& Grusec, 1983). Additionally, harsh discipline may undermine the parent-child relationship and decrease children's desire to internalize parental values (e.g., Grusec \& Goodnow, 1994; Hirschi, 1969). Through these channels, the experience of physical punishment may interfere with the internalization of parental norms, resulting in more frequent violations of standards of conduct, and ultimately more significant externalizing behavior problems. Second, full and partial mediation effects with respect to induction are consistent with the theory that parents who explain and remind children of rules and the consequences of their behavior on others may influence the expression of externalizing behavior problems, in part, by facilitating children's development of internalized self-control according to standards of conduct (e.g., Gardner \& Ward, 2000). Third, though more tentative, findings are consistent with the theory that parental discipline and socialization efforts made in a nurturant and responsive spirit encourage children to attend to and accept parental messages regarding acceptable conduct, and perhaps come to experience them as self-generated (e.g., Grusec \& Goodnow, 1994; Hoffman, 1983). By these channels, warm discipline processes that support the development of early child conscience may impact whether children show externalizing behavior problems.

In addition to mediation effects, inductive and physical discipline had significant associations with externalizing symptoms that persisted even after controlling for moral regulation (i.e., direct effects). Several mechanisms are possible. Physical discipline may have direct effects on externalizing because it models aggression (e.g., Bandura, Ross, \& Ross, 1961) and may initiate and perpetuate coercive cycles of parent-child aversive behavior that generalize to other contexts (e.g., Patterson, Dishion, $\&$ Bank, 1984). Also, the measures of induction used here may encompass reminding of rules and reasoning about external behavioral contingencies, in addition to the types of induction that are thought to relate to conscience development (Hoffman, 1983). That is, some components of induction may serve to regulate externalizing problems in a manner that does not depend on the internalization of norms. Further research is needed that disentangles these components of inductive discipline styles. 


\section{Moderating Effects of Child Gender}

In this study, individual differences in moral regulation were negatively associated with externalizing behaviors in both sexes. However, child gender strongly moderated associations between parental discipline and both child moral regulation and externalizing problems, a finding that is consistent with recent meta-analyses (Gershoff, 2002; Rothbaum \& Weisz, 1994). Although parental discipline and boys' behavioral outcomes were consistently associated, variations in parental disciplinary practices generally were unrelated to girls' externalizing behaviors or moral regulation. To explain this, we explored whether parents used less warmth and induction and higher levels of punishment with sons than with daughters. However, this notion was not supported in this study. It is possible that, although parents may use similar discipline methods with boys and girls, they may deploy them in response to different types of transgressions, as shown in work by Smetana (1989). In any case, findings may have important implications for our understanding of gender differences in the development of externalizing behavior problems. That is, whereas sex differences in the frequency of disruptive behavior are negligible before age 4 (e.g., Achenbach et al., 1987; Hay, Castle, \& Davies, 2000), henceforth boys show higher levels of externalizing problems than do girls (Keenan \& Shaw, 1997; Tremblay, Pihl, Vitaro, \& Dobkin, 1994). Developmental and social processes underlying this intriguing pattern remain unspecified. Thus, in future longitudinal work with this sample, we intend to investigate whether gender-differentiated antecedents of behavioral adjustment may influence the trajectories of early behavior problems.

\section{Comparing Maternal and Paternal Discipline as Correlates of Boys' Adjustment}

A contribution of this study was the inclusion of fathers' reports of disciplinary practices and child adjustment. Phares and Compas (1992) have emphasized the importance of considering the influence of fathers on child psychopathology. Recent reports have suggested that fathers' disciplinary practices may play an important role in the stability of early behavior problems (e.g., DeKlyen et al., 1998; Denham et al., 2000). We found that both parents' disciplinary practices were significantly associated with variations in boys' behavioral adjustment. Notably, however, paternal discipline reports had more cross-informant associations, while associations among maternal discipline, child externalizing, and moral regulation appeared to be situationally specific. Additionally, those parenting practices that were associated with child behavioral outcomes differed for mothers and fathers. Maternal reports of less frequent physical punishment and greater use of induction predicted fewer externalizing behaviors and greater levels of moral regulation among boys, whereas maternal warmth overlapped with other discipline variables as a predictor. In contrast, paternal warmth was a robust predictor of lower levels of boys' externalizing behavior and also was associated greater levels of boys' moral regulation. Results also suggest that fathers' discipline may be characterized by less warmth and inductive control than mothers.' Thus, results confirm that paternal influences and reports are not redundant with those of mothers and that they contribute significantly to variations in child outcomes.

Further research is needed to determine how and why different components of maternal and paternal discipline are associated with boys' adjustment. For example, disciplinary practices of mothers and fathers may carry meanings and expressive components that differentially affect child behavior (Grusec \& Goodnow, 1994). For example, even when mothers and fathers endorse similarly high levels of warmth, the manner in which warmth is expressed and understood by their children may differ. In future research, we will examine these issues in analyses of direct observations of parent-child interactions.

\section{Limitations}

There are several limitations of this study. First, most of the significant findings involved parent report measures. Although measures of child adjustment were bolstered with observations and teacher reports, future research should include observational measures of relevant parenting and discipline behaviors. Second, most participants came from intact, two-parent, middle-class families. Thus, the present results may be less applicable to children developing in other family constellations, or to those whose families are economically underprivileged. Third, most children were of Euro-American backgrounds, potentially limiting the generalizability of our findings to other racial and ethnic groups. Importantly, others have argued that cultural norms (that may vary by ethnicity and social class) may moderate effects of parental discipline on child outcomes (e.g., Deater-Deckard \& Dodge, 1997).

Fourth, although children were recruited to represent the range of the externalizing problems spectrum, most did not have externalizing scores in the clinical range. Thus, findings may not generalize to clinically referred populations. Similarly, although some physical discipline was reported by a majority of cases, few reported extremely 
frequent use of such tactics. This may have affected the relatively modest magnitude of associations between physical discipline and child outcomes (e.g., Deater-Deckard \& Dodge, 1997; Gershoff, 2002).

Finally, data were cross-sectional assessments from the first wave of an ongoing longitudinal study. For this reason, inferences about causal influences of parental discipline on child adjustment cannot be made. In future research with this sample, we will be able to determine whether parental discipline styles predict moral regulation and externalizing behavior problems across the transition from preschool to school.

\section{GENERAL SUMMARY}

In conclusion, parental induction and warmth were linked with positive child functioning, as reflected in selfregulation according to standards of conduct and fewer externalizing problems. Conversely, physical punishment was associated with lower moral regulation and more severe behavior problems. Findings were consistent with a mediation model wherein parental discipline may have direct relationships with behavior problems, but also may indirectly affect the expression of externalizing problems via influences on early conscience. Importantly, effects were found only among boys, suggesting that different developmental processes may be associated with early externalizing problems for boys and girls. Results also confirm the importance of fathers' contributions to our understanding of the origins of child externalizing problems.

\section{ACKNOWLEDGMENTS}

This research was supported by a grant from the National Institute of Mental Health (RO1MH57489) to Sheryl Olson and Arnold Sameroff.

The authors thank the children, parents, teachers, and preschool administrators who participated in the study, and the many individuals who gave us invaluable help with administrative support and data collection, especially Gail Benninghoff, Meribeth Pezda, Felicia Kleinberg, Kathleen Lesko, and Leah Abeles.

\section{REFERENCES}

Achenbach, T. M. (1992). Manual for the Child Behavior Checklist/2-3 and 1992 profile. Burlington: University of Vermont, Department of Psychiatry.

Achenbach, T. M. (1997). Guide for the Caregiver-Teacher Report Form for Ages 2-5. Burlington: University of Vermont, Department of Psychiatry.
Achenbach, T. M., Edelbrock, C., \& Howell, C. T. (1987). Empirically based assessment of the behavioral/emotional problems of 2- and 3-year-old children. Journal of Abnormal Child Psychology, 15, 629-650.

Achenbach, T. M., \& Rescorla, L. A. (2001). Manual for the ASEBA School-Age Forms \& Profiles. Burlington: University of Vermont, Research Center for Children, Youth, \& Families.

American Psychiatric Association. (2000). Diagnostic and statistical manual of mental disorders (4th ed., Rev.). Washington, DC: Author.

Bandura, A., Ross, D., \& Ross, S. A. (1961). Transmission of aggression through imitation of aggressive models. Journal of Abnormal and Social Psychology, 63, 575-582.

Baron, R. M., \& Kenny, D. A. (1986). The moderator-mediator variable distinction in social psychological research: Conceptual, strategic, and statistical considerations. Journal of Personality and Social Psychology, 51, 1173-1182.

Campbell, S. B. (1995). Behavior problems in preschool children: A review of recent research. Journal of Child Psychology and Psychiatry, 36, 113-149.

Campbell, S. B., Shaw, D. S., \& Gilliom, M. (2000). Early externalizing behavior problems: Toddlers and preschoolers at risk for later maladjustment. Development and Psychopathology, 12, 467-488.

Deater-Deckard, K., \& Dodge, K. A. (1997). Externalizing behavior problems and discipline revisited: Nonlinear effects and variation by culture, context, and gender. Psychological Inquiry, 8, 161-175.

DeKlyen, M., Biernbaum, M. A., Speltz, M. L., \& Greenberg, M. T. (1998). Fathers and preschool behavior problems. Developmental Psychology, 34, 264-275.

Denham, S. A., Workman, E., Cole, P. M., Weissbrod, C., Kendziora, K. T., \& Zahn-Waxler, C. (2000). Prediction of externalizing behavior problems from early to middle childhood: The role of parental socialization and emotion expression. Development and Psychopathology, 12, 23-45.

Dix, T., \& Grusec, J. E. (1983). Parental influence techniques: An attributional analysis. Child Development, 54, 645-652.

Dodge, K. A., Pettit, G. S., \& Bates, J. E. (1994). Socialization mediators of the relation between socioeconomic status and child conduct problems. Child Development, 65, 649-665.

Eisenberg, N., Cumberland, A., Spinrad, T. L., Fabes, R., Shepard, S., Reiser, M., et al. (2001). The relations of regulation and emotionality to children's externalizing and internalizing problem behavior. Child Development, 72, 1112-1134.

Eisenberg, N., Losoya, S., \& Fabes, R. A. (2001). Parental socialization of children's dysregulated expression of emotion and externalizing problems. Journal of Family Psychology, 15, 183-205.

Fagot, B. I., \& Hagan, R. (1991). Observations of parent reactions to sexstereotyped behaviors: Age and sex effects. Child Development, 62, 617-628.

Gardner, F., \& Ward, S. (2000). Parent-child interaction and children's well-being: Reducing conduct problems and promoting conscience development. In A. Buchanan (Ed.), Promoting children's emotional well-being (pp. 95-127). New York: Oxford University Press.

Gershoff, E. T. (2002). Corporal punishment by parents and associated child behaviors and experiences: A meta-analytic and theoretical review. Psychological Bulletin, 128, 539-579.

Grusec, J. E., \& Goodnow, J. J. (1994). Impact of parental discipline methods on the child's internalization of values: A reconceptualization of current points of view. Developmental Psychology, 30, 4-19.

Grusec, J. E., \& Kuczynski, L. (1980). Direction of effect in socialization: A comparison of the parent's versus the child's behavior as determinants of disciplinary techniques. Developmental Psychology, 16, 1-9.

Hastings, P. D., Zahn-Waxler, C., Robinson, J., Usher, B., \& Bridges, D. (2000). The development of concern for others in children with behavior problems. Developmental Psychology, 36, 531-546.

Hay, D. F., Castle, J., \& Davies, L. (2000). Toddlers' use of force against familiar peers: A precursor of serious aggression? Child Development, 71, 457-467. 
Hinshaw, S. P., \& Nigg, J. T. (1999). Behavior rating scales in the assessment of disruptive behavior problems in childhood. In D. Shaffer, C. P. Lucas, \& J. E. Richters (Eds.), Diagnostic assessment in child and adolescent psychopathology (pp. 91-126). New York: Guilford Press.

Hirschi, T. (1969). Causes of delinquency. Berkeley: University of California Press.

Hoffman, M. L. (1983). Affective and cognitive processes in moral internalization: An information processing approach. In E. T. Higgins, D. Ruble, \& W. Hartup (Eds.), Social cognition and social development: A socio-cultural perspective (pp. 236-274). Cambridge, England: Cambridge University Press.

Hoffman, M. L. (1994). Discipline and internalization. Developmental Psychology, 30, 26-28.

Hoffman, M. L. (2000). Empathy and moral development: Implications for caring and justice. New York: Cambridge University Press. Hoffman, M. L., \& Saltzstein, H. D. (1967). Parent discipline and the child moral development. Journal of Personality and Social Psychology, 5, 45-57.

Judd, C. M., \& Kenny, D. A. (1981). Process analysis: Estimating mediation in treatment evaluations. Evaluation Review, 5, 602-619.

Keenan, K., \& Shaw, D. (1997). Developmental and social influences on young girls' early problem behavior. Psychological Bulletin, $121,95-113$

Keenan, K., Shaw, D., Delliquadri, E., Giovannelli, J., \& Walsh, B. (1998). Evidence for the continuity of early problem behaviors: Application of a developmental model. Journal of Abnormal Child Psychology, 26, 441-454.

Keenan, K., \& Wakschlag, L. S. (2000). More than the terrible twos: The nature and severity of behavior problems in clinic-referred preschool children. Journal of Abnormal Child Psychology, 28, 33-46.

Kochanska, G. (1993). Toward a synthesis of parental socialization and child temperament in early development of conscience. Child Development, 64, 325-347.

Kochanska, G. (1997). Multiple pathways to conscience for children with different temperaments from toddlerhood to age 5 . Development Psychology, 33, 228-240.

Kochanska, G., \& Aksan, N. (1995). Mother-child mutually positive affect, the quality of child compliance to requests and prohibitions, and maternal control as correlates of early internalization. Child Development, 66, 236-254.

Kochanska, G., DeVet, K., Goldman, M., Murray, K., \& Putnam, S. (1994). Maternal reports of conscience development and temperament in young children. Child Development, 65, 852868.

Kochanska, G., Gross, J. N., Lin, M., \& Nichols, K. E. (2002). Guilt in young children: Development, determinants, and relations with a broader system of standards. Child Development, 73, 461-482.

Kochanska, G., \& Murray, K. (2000). Mother-child mutually responsive orientation and conscience development: From toddler to early school age. Child Development, 71, 417-431.

Kochanska, G., Murray, K., Jacques, T. Y., Koenig, A. L., \& Vandegeest, K. A. (1996). Inhibitory control in young children and its role in emerging internalization. Child Development, 67, 490-507.

Krevans, J., \& Gibbs, J. C. (1996). Parents' use of inductive discipline: Relations to children's empathy and prosocial behavior. Child Development, 67, 3263-3277.

Loeber, R., Lahey, B. B., \& Thomas, C. (1991). Diagnostic conundrum of oppositional defiant disorder and conduct disorder. Journal of Abnormal Psychology, 100, 379-390.

Maccoby, E. E., \& Martin, J. A. (1983). Socialization in the context of the family: Parent-child interaction. In E. M. Hetherington (Ed.),
Mussen manual of child psychology (4th ed., Vol. 4, pp. 1-102). New York: Wiley.

MacKinnon, D. P., Warsi, G., \& Dwyer, J. H. (1995). A simulation study of mediated effect. Multivariate Behavioral Research, 30, 41-62.

MacQuiddy, S. L., Maise, S. J., \& Hamilton, S. B. (1987). Empathy and affective perspective-taking skills in parent-identified conduct-disordered boys. Journal of Clinical Child Psychology, $16,260-268$.

Nobes, G., \& Smith, M. (1997). Physical punishment of children in two-parent families. Clinical Child Psychology and Psychiatry, 2, 271-281.

Nobes, G., Smith, M., Upton, P., \& Heverin, A. (1999). Physical punishment by mothers and fathers in British homes. Journal of Interpersonal Violence, 14, 887-902.

Olson, S. L., Bates, J. E., Sandy, J. M., \& Lanthier, R. (2000). Early developmental precursors of externalizing behavior in middle childhood and adolescence. Journal of Abnormal Child Psychology, 28, 119-133.

Olson, S. L., Kerr, D. C. R., Sameroff, A. J., \& Lopez, N. L. (2004). Conscience development in young children at risk for school-age externalizing problems. Manuscript submitted for publication.

Olson, S. L., \& Sameroff, A. J. (1997). Social risk and self-regulation problems in early childhood. Bethesda, MD: National Institute of Mental Health.

Olson, S. L., Sameroff, A. J., Kerr, D. C. R., Lopez, N. L., \& Wellman, H. M. (2004). Developmental foundations of externalizing problems in young children: The role of effortful control. Development and Psychopathology.

Patterson, G. R., Dishion, T. J., \& Bank, L. (1984). Family interaction: A process model of deviancy training. Aggressive Behavior, 10, 253-267.

Phares, V., \& Compas, B. E. (1992). The role of fathers in child and adolescent psychopathology: Make room for daddy. Psychological Bulletin, 111, 387-412.

Power, T. G., Kobayashi-Winata, H., \& Kelley, M. L. (1992). Childrearing patterns in Japan and the United States: A cluster analytic study. International Journal of Behavioral Development, 15, 185-205.

Preacher, K. J., \& Leonardelli, G. J. (2001). Calculation for the Sobel test: An interactive calculation tool for mediation tests. Retrieved July 22, 2003, from University of North Carolina at Chapel Hill Web site: http://www.unc.edu/ preacher/sobel/sobel.htm

Rothbart, M. K., \& Bates, J. E. (1998). Temperament. In W. Damon \& N. Eisenberg (Eds.), Handbook of child psychology (5th ed., Vol. 3, pp. 105-176). New York: Wiley.

Rothbaum, F., \& Weisz, J. R. (1994). Parental caregiving and child externalizing behavior in nonclinical samples: A meta-analysis. Psychological Bulletin, 116, 55-74.

Schachar, R. (1991). Childhood hyperactivity. Journal of Child Psychology and Psychiatry, 32, 155-191.

Smetana, J. G. (1989). Toddlers' social interaction in the context of moral and conventional transgression in the home. Developmental Psychology, 25, 499-508.

Straus, M. A., \& Stewart, J. H. (1999). Corporal punishment by American parents: National data on prevalence, chronicity, severity, and duration, in relation to child and family characteristics. Clinical Child and Family Psychology Review, 2, 55-70.

Tremblay, R. E., Pihl, R. O., Vitaro, F., \& Dobkin, P. L. (1994). Predicting early onset of male antisocial behavior from preschool behavior. Archives of General Psychiatry, 51, 732-739.

Zahn-Waxler, C., Cole, P. M., Welsh, J. D., \& Fox, N. A. (1995). Psychophysiological correlates of empathy and prosocial behaviors in preschool children with behavior problems. Development and Psychopathology, 7, 27-48. 